\title{
VANCOMYCIN. HYDROLYSIS AND OXIDATION STUDIES
}

\author{
A. W. Johnson* and Roger M. SMith ${ }^{\dagger}$ \\ School of Molecular Sciences, University of Sussex, Falmer, Brighton \\ B N1 9 QJ, United Kingdom
}

(Received for publication Februarry 28, 1972)

Further hydrolytic and oxidation studies on the antibiotic vancomycin have resulted in a revision of the structure of one of the aromatic units and the identification of $\mathrm{N}$-methylleucine as a terminal group.

The broad spectrum antibiotic vancomycin was isolated from Streptomyces orientalis in $1956^{1)}$, but its structure has not yet been elucidated. Early degradative studies ${ }^{2}$ showed that glucose, aspartic acid and an unidentified ninhydrin-positive compound were formed on hydrolysis. The elemental formula of vancomycin suggested a peptide type structure and showed that the molecule contained two covalent chlorine atoms assuming a molecular weight of 1,650. Titration indicated the presence of carboxyl, amino, and phenolic groups. Further studies ${ }^{3,4}$ showed that the second amino-acid was D-N-methylleucine and that there was one glucose and one aspartic acid unit in the vancomycin molecule of molecular weight 1,650. Prolonged acid treatment of vancomycin yielded laevulinic acid, 'vancomycin acid', $\mathrm{CH}_{3} \cdot \mathrm{CH}_{2} \cdot \mathrm{CO} \cdot \mathrm{CH}-$ $\left(\mathrm{CH}_{3}\right) \cdot \mathrm{CH}_{2} \cdot \mathrm{CO}_{2} \mathrm{H}$, and oxidation with nitric acid gave a high yield of 2-chloro-4,6dinitrophenol, and traces of 3,5-dinitrosalicylic acid and picric acid. When vancomycin was partially nitrated and then oxidised with alkaline permanganate, 3-chloro-4hydroxybenzoic acid and 3-chloro-4-hydroxy-5-nitrobenzoic acid were formed. Thus the structural units (I) and (II) were identified in vancomycin.

Vancomycin is one member of a group of related peptide antibiotics, the other members being actinoidin, ristocetin, and ristomycin ${ }^{5)}$ which are being studied extensively in Hungary and U.S.S.R. A common amino-sugar of unknown structure has been reported ${ }^{6)}$ as a constituent of these antibiotics and their molecular, weights and<smiles>Clc1ccc(Cl)c(Cl)c1</smiles>

(1)<smiles>Clc1ccccc1Cl</smiles>

(II) ionogenic groups also have been studied and compared ${ }^{7)}$. The Soviet group reported that vancomycin had a molecular weight of $c a$. 1,600 and contained there phenolic groups, one primary amino and one secondary or tertiary amino group. We have reported recently ${ }^{8)}$ on our studies of the amino-sugar vancosamine (III) released from vancomycin on mild acid hydrolysis. Vancosamine which contained a primary amino group unsubstituted in the intact antibiotic, probably identical with, or related to, the amino-sugar studied by LomakinA et al.

Acetylation of vancomycin with methanolic acetic anhydride or acetic anhydridepyridine followed by methanolysis gave a good yield of $\mathrm{N}$-acetyl-N-methyl-leucine $f$ Present address: School of Natural Resources, University of the South Pacific, Suva, Fiji. 
methyl ester together with a small amount of partially acetylated vancosamine. Thus the $\mathrm{N}$-methyl group of $\mathrm{N}$-methylleucine is apparently free in vancomycin and represents the secondary amino group reported earlier?). Furthermore, the ready methanolysis suggested that the leucine carboxyl group was linked to the rest of the molecule by an ester rather than an amide linkage. Restricted rotation about the acetylnitrogen bond in N-acetyl-N-methyl-leucine methyl ester causes the ester-methyl and $\mathrm{N}$-methyl n.m.r. signals to be split (ratio $1: 5$ ).

On more vigorous degradation with either $6 \mathrm{~N}$ hydrochloric acid, or $0.05 \mathrm{~N}$ hydrochloric acid and Amberlite IR-120( $\left.\mathrm{H}^{+}\right)^{9)}$, vancomycin gave a mixture of amino-acids from which aspartic acid and $\mathrm{N}$-methylleucine were readily isolated. Contrary to previous reports ${ }^{3,4}$, an examination of the mixture on an amino-acid analyser recorded only aspartic acid; neither glycine nor alanine was detected. N-Methylleucine reacts too slowly with ninhydrin to be recorded under these conditions ${ }^{10)}$. Separation of the hydrolysis products on ion-exchange columns followed by methylation and acetylation gave a number of chlorine-free aromatic compounds apparently containing acetylated phenolic groups. Unfortunately insufficient material was available for further structural studies.

As reported earlier ${ }^{3,4)}$, ammonia was evolved during alkaline hydrolyses of vancomycin, but no useful products could be identified. Alkaline or acid hydrolyses of methylated vancomycin likewise failed to give any identifiable products.

Vancomycin was heated under reflux with nitric acid for 5 hours rather than 19 hours as previously described ${ }^{4}$, and the products were methylated with diazomethane and separated to give 2-chloro-4,6-dinitrophenol and 2-chloro-4,6-dinitroanisole from structural unit (I) and picric acid and methyl 2-methoxy-3,5-dinitrobenzoate from unit (II). The isolation also of $\mathrm{N}$-methyl-N-nitrosoleucine methyl ester (action of nitrogen dioxide formed during the reaction on the free secondary amine ${ }^{11)}$ confirmed the presence of the terminal $\mathrm{N}$-methyl group. The reaction of nitric acid on an acylated secondary amine would have been expected to yield a nitramine. Degradation of vancomycin with nitric acid at room temperature followed by methylation gave only 2-chloro-4-nitrophenol, 2-chloro-4-nitroanisole and 2-chloro-4,6-dinitroanisole, all from unit (I).

Earlier attempts ${ }^{4)}$ to obtain useful products from vancomycin by oxidation with alkaline permanganate had been unsuccessful but in the present work permanganate oxidation followed by methylation of the acidic products with diazomethane gave methyl 3-chloro-4-hydroxybenzoate from unit (I) and dimethyl 4-hydroxyisophthalate. The latter product must be formed from a unit (IV) which under nitration conditions could be degraded to unit (II).

When aglucovancomycin ${ }^{4)}$ was methylated with an excess of alkaline dimethyl sulphate and then oxidized with permanganate, the acid fraction, after methylation, yielded methyl 3-chloro4-methoxybenzoate, dimethyl 4-hydroxy- and 4methoxy-isophthalates. Thus the oxygen atom

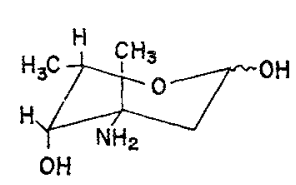

(III)<smiles>O=[W]c1ccc(Cl)cc1Cl</smiles>

(N) 
of unit (IV) is apparently hindered in vancomycin and is partly protected from methylation. From both permanganate oxidations, products were isolated that were apparently ethers of methyl 3-chloro-4-hydroxybenzoate but the ether substituent has not yet been identified. The low yields of aromatic products obtained from these reactions are no doubt due to the instability of phenols to permanganate oxidation.

Thus the following fragments are contained in the vancomycin molecule: glucose, vancosamine, aspartic acid, N-methylleucine, two moieties of unit (I) and one of unit (IV), but collectively these still account only for about half of the observed value of 1,650 for the molecular weight.

\section{Experimental}

\section{General}

I.r. spectra were meaured on a Perkin Elmer 257 and ultraviolet spectra on a Unicam SP 6000 instrument. N.m.r. spectra were measured on a Varian HA-100 in deuteriochloroform solutions unless otherwise stated. Optical rotations were determined using a 2-cm cell on a Perkin Elmer 141 instrument. Mass spectra were measured either on a Perkin Elmer Hitachi R.M.U. 6-E or A.E.I. M.S. 9 instrument. Microanalyses were carried out by Mr. A. Olney of this School. T.l.c. was carried out on Kiesel gel $\mathrm{GF}_{254}$ and light petroleum refers to the fraction b.p. $60 \sim 80^{\circ} \mathrm{C}$.

Vancomycin

Vancomycin sulphate and free base were supplied by Eli Lilly and Co. and were used without further purification.

Mild acetylation of vancomycin

A solution of vancomycin $(5.3 \mathrm{~g})$ in pyridine $(25 \mathrm{ml})$ was treated overnight with acetic anhydride $(10 \mathrm{ml})$ at room temperature. The solution was diluted with methanol and evaporated. The product was dissolved in $1 \mathrm{~N}$ methanolic hydrogen chloride $(100 \mathrm{ml})$ and heated under reflux for 7 hours. The solution was evaporated and the residue dissolved in $0.5 \%$ aqueous sodium bicarbonate $(300 \mathrm{ml})$. The solution was extracted with ethyl acetate and the extract on drying and evaporation gave a gum $(684 \mathrm{mg})$. Separation by t.l.c. (ether) gave $\mathrm{N}$-acetyl-N-methylleucine methyl ester $(155 \mathrm{mg}), \mathrm{Rf} 0.5$, as a fluid oil, and a gum $\left(53 \mathrm{mg}\right.$ ), Rf 0.3 . The ester gave a single peak on g.l.c. and it showed $\nu_{\max }$. (film) $1745,1657 \mathrm{~cm}^{-1}$. The mass spectrum contained prominent peaks at $m / e 201\left(\mathrm{M}^{+}\right), 142\left(\mathrm{M}^{+}\right.$ $-59)$ and $100\left(\mathrm{M}^{+}-59-42\right)$. The n.m.r. spectrum $\left(\mathrm{CDCl}_{3}\right)$ showed $\tau 9.01\left[\mathrm{~d}, \mathrm{CH}\left(\mathrm{CH}_{3}\right)_{2}\right]$, $8.4\left[\mathrm{~m}, \mathrm{CH}\left(\mathrm{CH}_{3}\right)_{2}\right], 7.85\left(s, \mathrm{CO} \cdot \mathrm{CH}_{3}\right), 7.15,7.10$ (both s, $\left.1: 5, \mathrm{~N} \cdot \mathrm{CH}_{3}\right), 6.35,6.30\left(\mathrm{~s}, \mathrm{CO}_{2} \mathrm{CH}_{3}\right)$, $4.70(\mathrm{dd}, J=7.8 \mathrm{~Hz}, \alpha-\mathrm{CH}$ ). The sample was identical (i.r., n.m.r., g.l.c.), i.e., apart from optical activity, with an authentic specimen prepared from L-leucine by acetylation $(\mathrm{MeOH}-$ $\mathrm{Ac}_{2} \mathrm{O}$ ) followed by $\mathrm{N}$-methylation (MeI- $\mathrm{NaH}$, method ${ }^{12)}$ ) then methylation of the carboxylic acid $\left(\mathrm{CH}_{2} \mathrm{~N}_{2}\right)$.

The gum of Rf 0.3 was purified by t.l.c. (ethyl acetate) to give a partially acetylated amino-sugar ${ }^{\mathrm{ef}}{ }^{13}$ ) which was not identified fully.

Vancomycin and $6 \mathrm{~N}$ Hydrochloric acid

A solution of vancomycin $(9.8 \mathrm{~g})$ in $6 \mathrm{~N}$ hydrochloric acid was heated under reflux for 20 hours. The solution was evaporated to dryness and the residue separated by chromatography on Amberlite IR-120 $\left(\mathrm{H}^{+}\right)$, which was first eluted with $0.01 \mathrm{~N}$ hydrochloric acid to give unreacted starting material and neutral components, then with distilled water to give an acid fraction (198 $\mathrm{mg}$ ) and finally with $10 \%$ ammonium hydroxide to yield an amino acid fraction $(2.8 \mathrm{~g})$. The amino acid fraction was partially fractionated on an Amberlite IR-120(Na+) column eluted with $0.2 \mathrm{~N}$ sodium citrate buffer solutions, to give first an acidic fraction and then a neutral amino acid fraction. The acidic amino acid fraction was freed from citrate ions on an Amberlite IR-120 $\left(\mathrm{H}^{+}\right)$column to give a mixture $(1.3 \mathrm{~g})$, which, on 
examination on an amino acid analyser contained only aspartic acid as a significant detectable component. The mixture was then run through a mild anion Amberlite IR- 45 column, to give the neutral amino acids $(760 \mathrm{mg})$, and after acid elution, the acidic amino acids (355 mg). The acidic amino acid fraction was treated with methanolic hydrogen chloride and then with acetic anhydride in pyridine to give a mixture containing two main components. Separation of these by column and t.l.c. yielded dimethyl $\mathrm{N}$-acetylaspartate $(40 \mathrm{mg})$ and a phenolic fraction which could apparently be resolved into two components by t.l.c. (both $\mathrm{M}^{+}$m/e 586).

The neutral amino-acid fraction was freed from citrate ions and separated by t.l.c. $\left[\mathrm{BuOH}-\mathrm{H}_{2} \mathrm{O}-\mathrm{HOAc}(5: 3: 2)\right]$ when $\mathrm{N}$-methylleucine was obtained.

The acid fraction from the first column was partitioned between ethyl acetate and aqueous sodium bicarbonate, and on acidification of the aqueous phase and further extraction yielded a mixture of acids $(78 \mathrm{mg})$. The acids were methylated with diazomethane, and the esters separated by chromatography on silica gel to give methyl laevulinate (20 $\mathrm{mg}$ ), $\nu_{\max }$ (film) $1735,1715 \mathrm{~cm}^{-1}$, identical (i.r., mass and n.m.r. spectra with an authentic specimen) and the methyl ester of 'vancomycin acid' $(8.4 \mathrm{mg}), \nu_{\max }$. (film) 1735 (ester), and 1711 (ketone) $\mathrm{cm}^{-1}$, mass spectrum: $m / e 158\left(\mathrm{M}^{+}\right), 129\left(\mathrm{M}-29, \mathrm{C}_{2} \mathrm{H}_{5}\right), 127(\mathrm{M}-31), 109,101,87$, 74 ; n.m.r. $\left(\mathrm{CDCl}_{3}\right): \tau 8.95$ (t), $8.92(\mathrm{~d}, J=6.5 \mathrm{~Hz}), 6.5$ (q, $\left.J=7 \mathrm{~Hz}\right), 6.4\left(\mathrm{~s}, \mathrm{OCH}_{3}\right)$.

Mild complete acid hydrolysis of vancomycin

A solution of vancomycin $(10 \mathrm{~g})$ in $0.05 \mathrm{~N}$ hydrochloric acid $(500 \mathrm{ml})$ was heated under reflux for 22 hours with Amberlite IR-120( $\left.\mathrm{H}^{+}\right)(100 \mathrm{~g})$. The aqueous solution was decanted and evaporated to dryness. The residue was mainly glucose but on extraction with ethyl acetate yielded 2,5-dimethyl-4-hydroxy-2-cyclopentenone ${ }^{\text {cf. }}{ }^{13)}$. The ion exchange resin was washed with $5 \%$ ammonium hydroxide to give a mixture of amino acids $(3 \mathrm{~g})$. The mixture was introduced onto a column of Amberlite IRA-400 ( $\left.\mathrm{OAc}^{-}\right)$and was eluted with $0.5 \mathrm{~N}$ acetic acid to give first a mixture of neutral amino-acids $(2.3 \mathrm{~g})$ and an aspartic acid fraction $(680 \mathrm{mg})$. The neutral amino acids were fractionated on an Amberlite IR-120 $(\mathrm{CG}-\mathrm{I})\left(\mathrm{H}^{+}\right)$column, which was eluted with $1 \mathrm{~N}$ to $4 \mathrm{~N}$ hydrochloric acid to give a number of fractions, which were partitioned by chromatography on silica gel to give, after elution with $n$-butanol-water-acetic acid $(5: 3: 2)$, initially $N$-methylleucine and then a mixture of aromatic compounds. The aromatic compounds were treated with methanolic hydrogen chloride and then with acetic anhydride in pyridine to give, on repeated t.l.c., four major components, all showing different but related n.m.r. spectra and t.l.c. properties but all being apparently isomeric and showing a mass peak at m/e 586 (an accurate mass on one sample gave a value of 586.1785). - Insufficient material was available for further study.

Vancomycin and hot nitric acid

A solution of vancomycin $(9.1 \mathrm{~g})$ in concentrated nitric acid $(50 \mathrm{ml})$ and water $(150 \mathrm{ml})$ was heated under reflux for 5 hours causing evolution of nitrogen dioxide. The solution was cooled overnight when yellow crystals $(1.4 \mathrm{~g})$ separated, which after recrystallisation were identified as 2-chloro-4,6-dinitrophenol $(1.1 \mathrm{~g})$ by comparison with authentic material, m.p. $113^{\circ} \mathrm{C}^{14)}$ (m.p., mixed m.p., i.r., u.v., and n.m.r. spectra). The,filtrate was extrated with ethyl acetate, and the extract dried and evaporated to give an oil $(1.6 \mathrm{~g})$, which was combined with the mother liquors from the recrystallisation. The mixture was partitioned between ethyl acetate and aqueous sodium bicarbonate and the acidic fraction $(1.0 \mathrm{~g})$ treated with diazomethane and the mixture of esters separated into non-polar and polar fractions (unesterified acids and 2-chloro-4,6-dinitrophenol) on a silica gel column. The non-polar fraction was separated by fractional sublimation to give a colourless oil (21 mg), b.p. $80 \sim$ $100^{\circ} \mathrm{C} / 0.5$ torr, and a pale yellow oil $(121 \mathrm{mg}), 100 \sim 150^{\circ} \mathrm{C} / 0.05$ torr. The more volatile material was purified by t.l.c. (ether-light petroleum) to give as a homogeneous (g.l.c.) oil, N-methyl-N-nitroso-leucine methyl ester $(12 \mathrm{mg}), \lambda_{\max }(\mathrm{MeOH}) 233 \mathrm{~nm} ; \nu_{\max }$ (film) 1745 (ester), $1460(\mathrm{~N}-\mathrm{NO}) \mathrm{cm}^{-1}$; n.m.r. $\left(\mathrm{CDCl}_{3}\right) \tau 9.05(\mathrm{~d}, J 7 \mathrm{~Hz}), 8.0 \sim 8.8(\mathrm{~m}), 7.0(\mathrm{~s}), 6.24(\mathrm{~s})$, $4.50(\mathrm{dd}, J 7.5,8.5 \mathrm{~Hz})$; mass spectrum, m/e $188\left(\mathrm{M}^{+}\right), 129\left(\mathrm{M}^{+}-59\right), 102,98,57$ (Found: 
C, $51.75 ; \mathrm{H}, 8.65 ; \mathrm{N}, 15.1 . \mathrm{C}_{8} \mathrm{H}_{16} \mathrm{~N}_{2} \mathrm{O}_{3}$ requires $\mathrm{C}, 51.05 ; \mathrm{H}, 8.57 ; \mathrm{N}, 14.88 \%$ ). The less volatile fraction was separated by t.l.c. (ether-light petroleum) to give 2-chloro-4,6-dinitroanisole $(15 \mathrm{mg}$ ) and methyl 3,5-dinitro-2-methoxybenzoate $(94 \mathrm{mg}$ ) both identical (m.p., mixed m.p., i.r., u.v., and n.m.r. spectroscopy) with authentic samples, m.p. $36^{\circ} \mathrm{C}^{15)}$ and $165^{\circ} \mathrm{C}^{1(i)}$ respectively.

The neutral fraction was dissolved in dilute hydrochloric acid, extracted with chloroform to give 2-chloro-4,6-dinitrophenol $(496 \mathrm{mg})$, and then with ethyl acetate to yield picric acid (292 mg).

Aglucovancomycin and cold nitric acid

A solution of aglucovancomycin $\left.{ }^{4}\right)(7 \mathrm{~g})$ in concentrated nitric acid $(50 \mathrm{ml})$ and water $(200 \mathrm{ml})$ was kept at $25^{\circ} \mathrm{C}$ for 15 minutes by cooling in an ice bath. Water $(200 \mathrm{ml})$ was added and the solution extracted with ether to give, after drying and evaporation of the extract, a yellow semi-solid $(277 \mathrm{mg}$ ). The solid was treated with ethereal diazomethane and the product was separated by t.l.c. (ether and then ether-light petroleum) to give 2chloro-4,6-dinitroanisole $(11 \mathrm{mg})$ and two other fractions which were mixtures. The first mixture was separated by sublimation to give 2-chloro-4-nitroanisole $(17 \mathrm{mg})$, m.p. $90 \sim$ $93^{\circ} \mathrm{C}$ (lit. ${ }^{17)} \mathrm{m}$. p. $94^{\circ} \mathrm{C}$ ), mass spectrum : m/e 189, $187\left(\mathrm{M}^{+}\right)$. The second more polar fraction $(71 \mathrm{mg})$ was extracted with alkali and the phenolic fraction $(43 \mathrm{mg})$ was sublimed at $80 \sim$ $100^{\circ} \mathrm{C} / 2$ torr to give 2-chloro-4-nitrophenol, m.p. $109 \sim 110^{\circ} \mathrm{C}$ (lit. ${ }^{18)}$ m.p. $111^{\circ} \mathrm{C}$ ); mass spectrum, 175, $173\left(\mathrm{M}^{+}\right)$. Both these crystalline aromatic compounds gave the anticipated n.m.r. and i.r. spectra.

Vancomycin and alkaline potassium permanganate

Potassium permanganate $(10 \mathrm{~g})$ was slowly added to a solution of vancomycin $(5.7 \mathrm{~g})$ in $1 \mathrm{~N}$ sodium hydroxide $(100 \mathrm{~m})$. The solution was diluted with water $(50 \mathrm{ml})$ and heated under reflux for 1 hour. The solution was acidified and sodium metabisulphite was added to give a clear solution, which was extracted with ether. The ethereal solution was extracted with aqueous sodium bicarbonate which was acidified and extracted with ether to give, after drying and evaporation, a gum ( $153 \mathrm{mg}$ ). The gum was treated with ethereal diazomethane to give a mixture of esters which was fractionated on t.1.c. (ether-light petroleum) to give two main fractions. The less polar fraction $(16 \mathrm{mg})$ on sublimation at $90 \sim 100^{\circ} \mathrm{C} / 1$ torr yielded dimethyl 4-hydroxyisophthalate, identical with authentic material m.p. $96^{\circ} \mathrm{C}$ (m.p., mixed m.p., u.v., i.r., and n.m.r. spectroscopy and mass spectrum). The more polar fraction $(95 \mathrm{mg}$ ) was further separated by t.l.c. (ether-light petroleum) to give a major fraction $(38 \mathrm{mg})$. This fraction was again purified by t.l.c. and then sublimation at $90 \sim 100^{\circ} \mathrm{C} / 2$ torr yielded methyl 3-chloro-4-hydroxybenzoate identical with authentic material, m.p. 106 $107^{\circ} \mathrm{C}^{19)}$ (m.p., mixed m.p., i.r., u.v., and n.m.r. spectroscopy and mass spectrum).

Methylation and oxidation of vancomycin

Dimethyl sulphate $(4 \mathrm{ml})$ was added dropwise to a solution of vancomycin sulphate $(6.5 \mathrm{~g})$ in $1 \mathrm{~N}$ sodium hydroxide $(100 \mathrm{~m} 1)$. The solution was heated under reflux for $1 \frac{1}{2}$ hour and then cooled. A solution of potassium permanganate $(15 \mathrm{~g})$ in water $(50 \mathrm{ml})$ was slowly added and the solution was heated under reflux for 30 minutes. Sulphur dioxide was then introduced into the mixture until a clear solution was obtained, which was then extracted with ethyl acetate. The organic fraction was extracted with aqueous sodium bicarbonate to give, after acidification and reextraction with ether, a mixture of acids ( $414 \mathrm{mg}$ ). The acids were treated with ethereal diazomethane and the product filtered through silica gel, to give a mixture of esters $(251 \mathrm{mg})$, which was fractionated by t.l.c. (ether-light petroleum) to yield dimethyl 4-hydroxyisophthalate $\left(18.5 \mathrm{mg}\right.$ ), m.p. $96^{\circ} \mathrm{C}^{20}$ ) a crude methoxyester $(53 \mathrm{mg})$, and a mixture of minor components. The methoxy-ester was sublimed at $90 \sim 110^{\circ} \mathrm{C} / 1$ torr to give a trace of dimethyl 4-hydroxyisophthalate and the main methoxyester fraction, which on t.l.c. yielded methyl 3-chloro-4-methoxybenzoate $(20 \mathrm{mg})$, m.p. $93 \sim 99^{\circ} \mathrm{C}$ (lit. ${ }^{19)}$ m.p. $\left.94 \sim 95^{\circ} \mathrm{C}\right) \nu_{\max } .\left(\mathrm{CHCl}_{3}\right) 1715,1603 \mathrm{~cm}^{-1}$ mass spectrum m/e 202, 200 
$\left(\mathrm{M}^{+}\right)$.

The minor components were separated by repeated t.l.c. and sublimation to give dimethyl 4-methoxyisophthalate $(8.3 \mathrm{mg})$ identical with authentic material, m.p. 97.5 98.5 ${ }^{\circ} \mathrm{C}^{21)}$, (m.p., i.r., u.v., and n.m.r. spectroscopy and mass spectrum).

The reaction also yielded three unidentified ethers of methyl 3-chloro-4-hydroxybenzoate.

\section{Acknowledgements}

This work was carried out during the tenure of an I.C.I. Fellowship (R.M.S.). We thank Dr. M. WALlis of the School of Biological Sciences, University of Sussex, for amino-acid analyses and to Eli Lilly and Co., Indianapolis, Indiana for a supply of vancomycin.

\section{References}

1) MoCormtck, M.H.; W.M. Stark, G.E. Pittenger, R.C. Prtrengar \& J.M. MoGulre: Vancomycin, a new antibiotic. I. Chemical and biological properties. Antibiotics Annual 1955/1956: 606 611, Medical Encyclopedia Inc., New York, 1956

2) Hrgains, H.M.; W. H. Harrison, G. M. Wild, H. R. Bungay \& M. H. MoCormuck : Vancomycin, a new antibiotic. VI. Purification and properties of vancomycin. Antibiotics Annual 1957/1958: 906 914, Medical Encyclopedia Inc., New York, 1958

3). Johrson, C. R.: A prospectus of the vancomycin structure. Diss. Abs. 2696, 1962

4) Marshatd, F.R.: Structure studies on vancomycin. J. Med. Chem. $8: 18 \sim 22,1965$

5) Brazhnikova, M. G.; N. N. Lomakina, F. Sztaricskai, M. Puskes, S. Makleit \& R. Bognar: Vancomycin-type antibiotics. Kém Közlemén. $27: 143 \sim 162,1967$

BOGNAR, R.: Results of Soviet-Hungarian cooperation in antibiotic research in Debrecen. Chemical investigation of actinoidin and restomycin. Acta Univ. Debrecen 185 200, 1968

6) Lomakina, N.N.; I. A. Spiridonova, R. Bognkr, M. Puskas \& F. Szrarickai : Deoxyaminosugar from ristomycin. Its isolation and properties. Antibiotiki $13: 975 \sim 978,1968$

7) Lomakina, N.N.; L.I. Muraveva \& M.S. Yurtina : Molecular weight and the number of ionogenic groups of ristomycins and related antibiotics. Antibiotiki $15: 21 \sim 24,1970$

8) Smith, R. M.; A. W. Johnson \& R. D. Guthrig: Vancosamine. A novel branched amino-sugar from the antibiotic vancomycin. Chem. Commun. 1972:361 362, 1972

9) Brazhnikova, M. G. \& M. K. Kudinova: Hydrolysis of some antibiotics and of their decomposition products in the presence of cation-exchange resins. Nature 200:167 168, 1963

10) Coggins, J.R. \& N. L. Benoiton: Determination of N-methylamino acids and their optical purity with an amino acid analyser. J. Chromatography $52: 251 \sim 256,1970$

11) White, E. H. \& W. R. FELDMAN : The nitrosation and nitration of amines and alcohols with nitrogen tetroxide. J. Amer. Chem. Soc. $79: 5832 \sim 5833,1957$

12) Coggins, J. R. \& N. L. Benorton: Synthesis of N-methylamino acid derivatives from amino acid derivatives using sodium hydride/methy1 iodide. Canad. J. Chem. 49:1968 1971, 1971

13) Smitr, R. M.; A. W. Johrson \& R. D. Guthrie: Vancosamine. The structure and configuration of a novel amino-sugar from the antibiotic vancomycin. J. Chem. Perkin Transactions, 1. In preparation, 1972

14) VAN ALPhEN, J.: Dimorphism of tetranitrobiphenyl derivatives. III. Rec. Trav. Chim. $51: 453$ $\sim 459,1932$

15) Sohouten,A.E.: Nitration and halogenation of 1,2-bis (phenylamino) ethane and its derivatives. I. Rec. Trav. Chim. $56: 541 \sim 561,1937$

16) Ulimann, F.: Studies of aromatic compounds with labile halogens. Annalen $366: 79 \sim 118,1909$

17) Krnc, H. \& I. M. Tonkin : Antiplasmodial action and chemical constitution. VIII. Guanidines and diguanides. J. Chem. Soc. $1946: 1063 \sim 1069,1946$

18) Barton, D. H. R.; W. H. Linneul \& N. Senror : 4(4'-Aminobenzenesulphonamino) pyrocatechol and some related compounds. Quart. J. Pharm. Pharmacol. 18:41 47, 1945

19) Auwers, K.: A note on derivatives of $p$-hydroxybenzoic acid and anisic acid. Chem. Ber. 30: $1473 \sim 1478,1897$

20) Loewenherz, R.: Preparation of unsymmetrical aminoisophthalic acid from o-toluidine. Chem. Ber. $25: 2795 \sim 2798,1892$

21) Bonner, W. A. \& J. I. Degraw: Ketones from 'white snakeroot' Eupatorium urticaefolium. Tetrahedron $18: 1295 \sim 1309$, 1962 